\title{
RESEARCH TRENDS OF MICROBIOLOGY
}

\author{
(Volume-2)
}
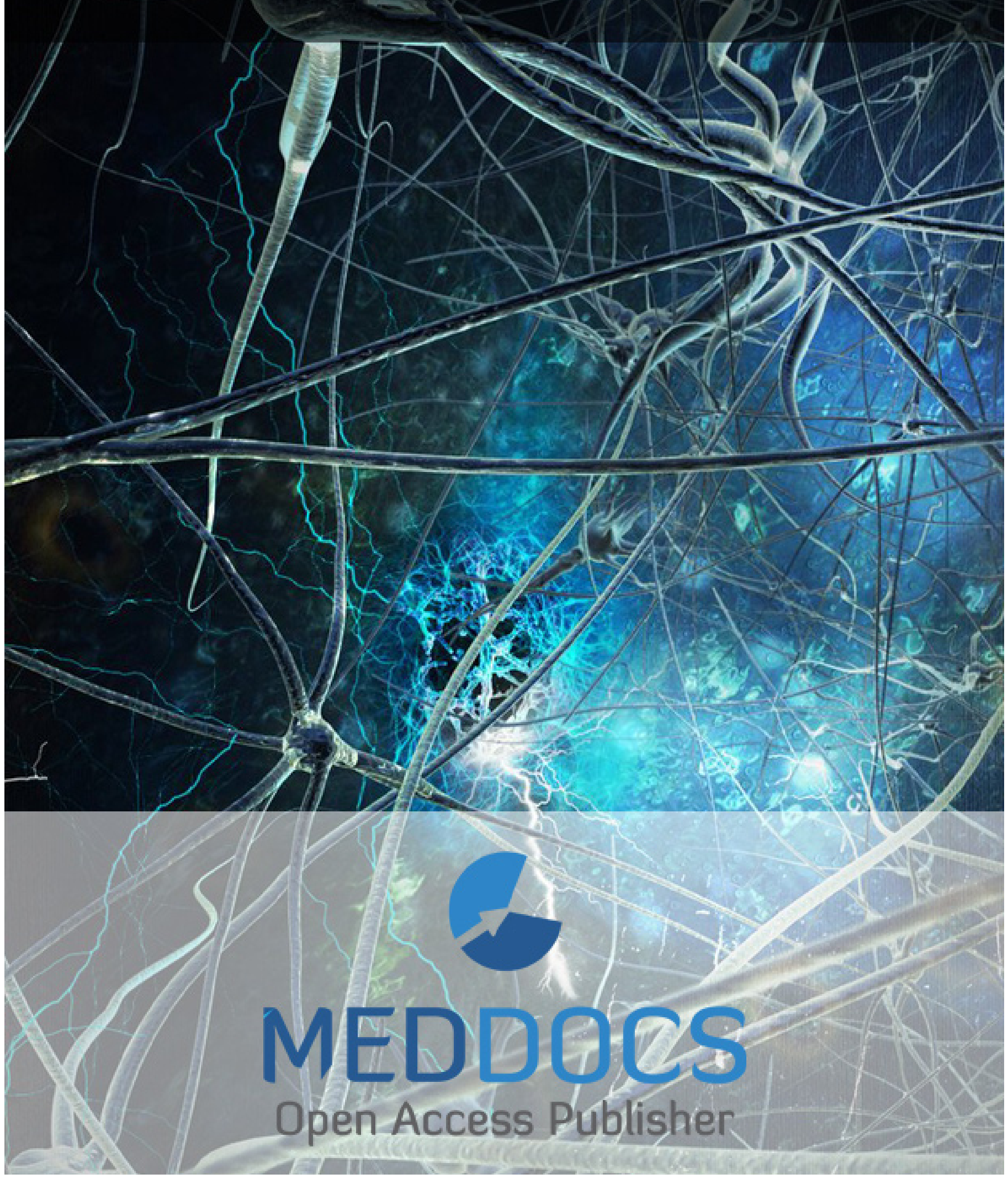


\title{
Investigation of Relevant Genes and Pathogenicity Factors in Multidrug-Resistant Acinetobacter Baumannii Strains Isolated from Clinical Specimens
}

\author{
Priscila Simão Costaㄹ ; Tassiane Assíria F Martins²; Luiz de Macêdo Farias ${ }^{1}$; Rafaela Oliveira França ${ }^{1}$; Cristina Dutra Vieira ; Van- \\ dack Nobre ${ }^{3}$; Ricardo Gonçalves ${ }^{2}$; Simone Gonçalves dos Santos ${ }^{1 *}$ \\ ${ }^{1}$ Laboratório de Microbiologia Oral e Anaeróbios, Instituto de Ciências Biológicas, Universidade Federal de Minas Gerais, Belo \\ Horizonte, MG, Brasil. \\ ${ }^{2}$ Laboratório de Patologia das Leishmanioses, Instituto de Ciências Biológicas, Universidade Federal de Minas Gerais, Belo Hori- \\ zonte, MG, Brasil. \\ ${ }^{3}$ Programa de Pós-Graduação em Infectologia e Medicina Tropical, Departamento de Clínica Médica, Faculdade de Medicina, \\ Universidade Federal de Minas Gerais, Belo Horizonte, MG, Brasil.
}

\section{Corresponding Author: Simone Gonçalves dos Santos}

Department of Microbiology, Institute of Biological Sciences, Federal University of Minas Gerais. Avenida Presidente Antônio Carlos, 6627, C.P. 486, Pampulha - UFMG Campus, 31270-901 Belo Horizonte, MG, Brazil

Tel: +55 31 3409-2743;

Email: simonesantoskey@ufmg.br

Published Online: Jul 07, 2020

eBook: Research Trends of Microbiology

Publisher: MedDocs Publishers LLC

Online edition: http://meddocsonline.org/

Copyright: (C) dos Santos SG (2020).

This chapter is distributed under the terms of Creative Commons Attribution 4.0 International License

Keywords: Acinetobacter baumannii; Pathogenicity; Oxidative stress; Biofilm; Cell death; Quorum sensing

\section{Abstract}

Acinetobacter baumannii has become a clinical and epidemiological relevant microorganism word wide. Several studies reveal aspects important to this pathogen to cause infectious disease, such as membrane proteins apoptosisinducing, biofilm formation, resistance to oxidative stress, besides of their potential to acquire antimicrobial resistance genes. However, the mechanisms underlying the success of this pathogen remain of great interest. This study evaluated some pathogenicity factors presented by strains of Multidrug-Resistant (MDR) A. baumannii isolated from different clinical specimens of patients in Belo Horizonte city, Brazil. Genes associated to the capsule, biofilm, apoptosisinducing and quorum sensing were researched by Polymerase Chain Reaction. The hemolytic activity of the strains in six blood types from three different mammalian species (sheep, horse and human blood type $A, B, O, A B$, all $R h$ positive) and the sensitivity to oxidative stress by hydrogen peroxide occurred by disc diffusion test. In vitro apoptosis was evaluated in bone marrow macrophages obtained from BALB/c mice. Overall, patients had mean age of 60.6 years ( \pm 17.6$)$ and most of them (95\%) were using some invasive device. All strains (29) were positive for gaiU and bap, $76 \%$ to $w z c, 86 \%$ to luxl and $79 \%$ luxR, $45 \%$ to omp33 and $31 \%$ to ompA genes. In the oxidative stress test, $49 \%$ were more resistant $(p<0.05)$ than the reference strains. In relation to in vitro tests, eight strains led to a significant reduction in the number of macrophages as compared to controls ( $p$ $<0.05$ ), among them $63 \%$ was positive to omp33 and ompA genes. The results show significant pathogenicity factors that contribute to the colonization and to the success of an infectious disease in hospitalized patients. Therefore, these data contributed to confirm the potential for aggression by these microorganisms, in addition to alerting to the need for constant improvements in nosocomial infection control protocols. 
Introduction

Healthcare-Associated Infections (HAls) are recognized as having a substancial impact on the lethality and morbidity of hospitalized patients, as well as on the social and economic costs to health systems [1]. In this context, Acinetobacter baumannii has been highlighted as an important opportunistic pathogen, responsible for a large percentage of HAls and also for hospital outbreaks [2].

Its ability to form biofilm on biotic surfaces plays an important role in nosocomial infections caused by this microorganism, which usually follows colonization of hospital equipment and medical devices [3]. In addition, other pathogenicity factors exhibited by $A$. baumannii representing a bacterial adaptation to or escape from challenges posed by the environment or by immune system of the host. Bacterial capsule are the most relevant of these factors [4]. It is believed that it provides a coating that protects cells from the external environment and also from phagocytosis [5].

Another mechanism of protection observed in Acinetobacter is the quorum sensing. This regulatory mechanism impacts the expression of a range of pathways that increase the persistence of this microorganism under hostile environmental conditions, such as dissection, nutrient restriction and antimicrobial treatments [4].

Hydrogen peroxide is a potent disinfectant with bactericidal activity and has been used to control Multidrug-Resistant $A$. baumannii (MDR) outbreaks in health care units. In addition, it plays a key role in containing bacterial infections by the immune system through phagocytes. This process is often referred to as a "respiratory burst", and is critical to contain and eliminate infection by the innate immune system. $A$. baumannii strains contain several genes encoding catalases, as well as Superoxide Dismutase (SOD), which leads to a different phenotype in relation to resistance to oxidative stress [10].

Despite its clinical importance, relatively little is known about the innate host defense mechanisms against respiratory A. baumannii infection. Recent studies have shown that the macrophage is an important phagocyte that is involved in host defense, and are crucial in the control of local bacterial. In this regard, play a critical role in host resistance against both intracellular and extracellular bacterial pathogens [5]. Several pathogens have been reported as inducers of cell death due to different mechanisms [6]. It's known that the exposure to purified OmpA protein leads to apoptosis of eukaryotic cells [7-9]. Omp33 protein also is capable of inducing apoptosis in eukaryotic cells, in addition to modulating autophagy, with the consequent accumulation of autophagosomes to avoid bacterial degradation [10].
In this study, we investigated some pathogenicity aspects presented by MDR A. baumannii strains, isolated from different clinical specimens of patients in Belo Horizonte city, Brazil. It was evaluated the presence of genes associated to virulence, tolerance to hydrogen peroxide, the hemolytic activity, as well as the induction of death of bone marrow derived macrophages.

\section{Materials and methods}

\section{Study design and characterization of patients}

The $A$. baumannii strains were isolated from specimens obtained from critically ill infected patients, admitted to the University Hospital of Universidade Federal de Minas Gerais state, from August 2012 to May 2013. This study was approved by the Research Ethics Committee (RCP Certificate of Presentation for Ethical Appreciation - CAAE - 01402312.60000.5149). The authorization for inclusion was obtained by signing the patients or legal guardians of the Informed Consent Term (ICT). Adult patients (age $\geq 18$ years) were included if they presented an acute infectious process related to $A$. baumannii, according to the treating physician judgment. The variables collectes upon inclusion wereas following: Invasive procedures performed during hospitalization; use of invasive medical devices during hospitalization; site of infection, presence of blood stream infection, presence of sepsis, admission to the Intensive Care Unit (ICU) and hospital mortality.

\section{Acinetobacter baumannii strains characterization}

All 29 A. baumannii strains were identified by the Vitek II system ${ }^{\circledR}$ and through the presence of the chromosomal gene bla $a_{\mathrm{OXA}-51}$. Strains showing to be resistance to at least one antimicrobial agent of three different classes were included in this study $[11,12]$. The reference strain, A. baumannii ATCC 19606, was used as control for all experiments.

All strains were submitted to antimicrobial susceptibility to Ampicillin-sulbactam (AB), Ceftazidime (TZ), Gentamicin (GM), Meropenem (MP), Polymyxin B (PO) and Tigecycline (TGC) by ETest ${ }^{\circledR}$. The PCR reaction was performed for detection of the following genes: bla $a_{\mathrm{OXA} 23}, b l a_{\mathrm{OXA24}}, b l a_{\mathrm{OXA51}}, b l a_{\mathrm{OXA} 58^{\prime}} b l a_{\mathrm{OXA} 143}, b l a_{\mathrm{VIM}-1{ }^{\prime}}$ csuE, ompA and insertion element ISAba1. The genetic diversity among the strains was evaluated by Enterobacterial Repetitive Intergenic Consensus (ERIC)-PCR, and phenotyping assays of biofilm formation on polystyrene microplate. All these tests were realized in previous study of the same research group [13].

\section{Detection of genes associated with pathogenicity}

The following genes related to induction to apoptosis in host cells, biofilm formation, quorum sensing and capsule presence were selected and screened using PCR: omp33,ompA, bap, luxl, IuxR, wzc and galU. The primers used are demonstrated in Table 1.

Table 1: Sequence of bases, amplicons and PCR reaction conditions used in the research of genetic determinants of pathogenicity factors.

\begin{tabular}{|c|c|c|c|c|c|}
\hline Gene & Pathogenicity factor & Primers sequence $\left(5^{\prime}-3^{\prime}\right)$ & Amplification conditions & Amplicon & Reference \\
\hline Bap & Biofilm formation & $\begin{array}{l}\text { PF 5'-TGCTGACAGTGACGTAGAACCACA-3' } \\
\text { PR 5'-TGCAACTAGTGGAATAGCAGCCCA-3' }\end{array}$ & $\begin{array}{l}\text { Initial denaturation } 95^{\circ} \mathrm{C}, 2 \mathrm{~min} ; 30 \mathrm{x}: 95^{\circ} \mathrm{C} \text {, } \\
45 \mathrm{~s} ; 61^{\circ} \mathrm{C}, 45 \mathrm{~s} \text {; Final extension: } 72^{\circ} \mathrm{C}, 1 \mathrm{~min} \text {. }\end{array}$ & $184 \mathrm{pb}$ & [22] \\
\hline ompA & $\begin{array}{l}\text { Induction of apopto- } \\
\text { sis in host cells }\end{array}$ & $\begin{array}{l}\text { PF 5'-GATGGCGTAAATCGTGGTA-3' } \\
\text { PR 5'-CAACTTTAGCGATTTCTGG-3' }\end{array}$ & $\begin{array}{l}\text { Initial denaturation } 94^{\circ} \mathrm{C}, 3 \mathrm{~min}, 30 \mathrm{x}: 94^{\circ} \mathrm{C} \text {, } \\
45 \mathrm{~s} ; 57^{\circ} \mathrm{C}, 45 \mathrm{~s} ; 72^{\circ} \mathrm{C}, 1 \mathrm{~min} \text {, Final extension: } \\
72^{\circ} \mathrm{C}, 5 \mathrm{~min} \text {. }\end{array}$ & $355 \mathrm{pb}$ & [33] \\
\hline omp33 & $\begin{array}{l}\text { Induction of apopto- } \\
\text { sis in host cells }\end{array}$ & $\begin{array}{l}\text { PF 5'-CAAGTGTTGCTAACCAATTCGCT-3' } \\
\text { PR 5'-GTTTTCTTGACCGAATGCACC-3' }\end{array}$ & $\begin{array}{l}\text { Initial denaturation } 94^{\circ} \mathrm{C}, 3 \mathrm{~min}, 30 \mathrm{x}: 94^{\circ} \mathrm{C} \text {, } \\
45 \mathrm{~s} ; 65^{\circ} \mathrm{C}, 45 \mathrm{~s} \text {; Final extension: } 72^{\circ} \mathrm{C}, 1 \mathrm{~min} \text {. }\end{array}$ & $194 \mathrm{pb}$ & [7] \\
\hline
\end{tabular}


MedDocs eBooks

\begin{tabular}{|c|c|c|c|c|c|}
\hline luxl & Quorumsensing & $\begin{array}{l}\text { PF 5'-GGTTGGGAG TTGAACTGTCC-3' } \\
\text { PR 5'-AAACGTTCTACTCCAAGAGG-3' }\end{array}$ & $\begin{array}{l}\text { Initial denaturation } 95^{\circ} \mathrm{C}, 2 \mathrm{~min}, 30 \mathrm{x}: 95^{\circ} \mathrm{C} \text {, } \\
45 \mathrm{~s} ; 58^{\circ} \mathrm{C}, 45 \mathrm{~s} \text {; Final extension: } 72^{\circ} \mathrm{C}, 1 \mathrm{~min} \text {. }\end{array}$ & $370 \mathrm{pb}$ & [34] \\
\hline $\operatorname{luxR}$ & Quorumsensing & $\begin{array}{l}\text { PF 5'-TCGGATTTGATTATTGCG CTTATG-3' } \\
\text { PR 5'-ACAGCTCGAATAGCTGCTG-3' }\end{array}$ & $\begin{array}{l}\text { Initial denaturation } 95^{\circ} \mathrm{C}, 2 \mathrm{~min}, 30 \mathrm{x}: 95^{\circ} \mathrm{C} \text {, } \\
45 \mathrm{~s} ; 58^{\circ} \mathrm{C}, 45 \mathrm{~s} \text {; Final extension: } 72^{\circ} \mathrm{C}, 1 \mathrm{~min} \text {. }\end{array}$ & $603 \mathrm{pb}$ & [34] \\
\hline$p t k(w z c)$ & Capsule & $\begin{array}{l}\text { PF 5'-CTCCACCAGTGCTTGCAGTA-3' } \\
\text { PR 5'-CAGCGCTAGCACGTTGAATA-3' }\end{array}$ & $\begin{array}{l}\text { Initial denaturation } 94^{\circ} \mathrm{C}, 3 \mathrm{~min}, 30 \mathrm{x}: 94^{\circ} \mathrm{C} \text {, } \\
45 \mathrm{~s} ; 60^{\circ} \mathrm{C}, 45 \mathrm{~s} \text {; Final extension: } 72^{\circ} \mathrm{C}, 1 \mathrm{~min} \text {. }\end{array}$ & $183 \mathrm{pb}$ & [5] \\
\hline gail & Capsule & $\begin{array}{l}\text { PF 5'-AGCCAAGCTGCTCAAATCAT-3' } \\
\text { PR 5'-CGGCCAACCACAGATAAGTT-3' }\end{array}$ & $\begin{array}{l}\text { Initial denaturation } 94^{\circ} \mathrm{C}, 3 \mathrm{~min}, 30 \mathrm{x}: 94^{\circ} \mathrm{C} \text {, } \\
45 \mathrm{~s} ; 60^{\circ} \mathrm{C}, 45 \mathrm{~s} \text {; Final extension: } 72^{\circ} \mathrm{C}, 1 \mathrm{~min} \text {. }\end{array}$ & $170 \mathrm{pb}$ & [5] \\
\hline
\end{tabular}

Footnote: PF: Forward; PR: Reverse

\section{Extraction of genomic DNA and preparation of master-mix}

DNA extraction from the $A$. baumannii strains was performed according to the Wizard ${ }^{\circledR}$ Genomic DNA Purification kit (Promega) methodology. The pre-mix kit 2X (Phoneutria), containing Taq DNA polymerase, the nucleotides (dATP, dGTP, dCTP, dTTP) and $\mathrm{MgCl}_{2}$, was used in the study. Each reaction occurred with $12.5 \mu \mathrm{l}$ of Pre-Mix + forward and reverse primers+ diluted bacterial DNA + nuclease-free water to complete the volume of $25 \mu l$.

\section{Phenotypic detection of pathogenicity factors}

\section{Evaluation of cell death induced by $A$. baumannii strains}

The induction of apoptosis in macrophages cells by A. baumannii was analyzed according to protocols published elsewhere [14]. These assays were performed with 20 studied strains: 19 strains that presented intergenic regions with more than $50 \%$ similarity by ERIC-PCR analyzes (date not shown) [13] and the reference (A. baumannii ATCC 19606).

\section{Obtaining bone marrow macrophages}

The cells used in this study were obtained from BALB/c mice, according to the bone marrow macrophage isolation protocol proposed by Gonçalves and Mosser [14]. Briefly, bone marrow was obtained by the femur and tibia of mice aged 6-10 weeks. Cells were placed on RPMI medium supplemented with $10 \%$ Fetal Bovine Serum, glutamine, penicillin/streptomycin and $10 \%$ conditioned media from $\mathrm{L} 929$ cells and maintained in $\mathrm{CO}_{2}$ greenhouse. At day 10, the cells were removed and used in the experiments.

\section{Preparation A. baumannii strains for infection}

Nineteen clinical strains were selected for this test, based on ERIC-PCR analyzes previously realized [13], presenting at least $50 \%$ of similarity. Bacterial strains were thawed and incubated in $5 \mathrm{~mL}$ of Tryptic Soy Broth (DIFCO ${ }^{\circ}$ ) medium for $24 \mathrm{~h}$. Subsequently they were centrifuged at $10.000 \mathrm{rpm}$ for 15 minutes. The strains were resuspended in complete RPMI medium without antimicrobials. For measurement of bacterial density 0.5 Mc Farland scale was used. An aliquot of $100 \mu \mathrm{L}$ of each dilution was used in the experiment.

\section{Cell culture in glass coverslips}

Macrophages were grown on $13 \mathrm{~mm}$ diameter glass cover slips, placed into 24 well culture plates, in complete antimicrobial RPMI medium, in a $97 \%$ humidified oven at $37^{\circ} \mathrm{C}$ and $5 \%$ $\mathrm{CO}_{2}$. They were plated at a density of $5 \times 10^{4}$ cells per well in $100 \mu \mathrm{L}$ and after $1 \mathrm{~h}$ of adhesion, bacterial cultures were added in the Multiplicity of Infection Index (MOI): 100. The experiment was performed in duplicate and the cell culture without bacterial inoculum was used as negative control. After the $24 \mathrm{~h}$ incubation period, the coverslips were stained with panoptic us and fixed in microscopy slides for evaluation under capture microscopy.

\section{Cell count}

Macrophages were photographed under a capture microscope (15 fields per coverslip), using the program Q Capture Pro 7 and counted through Image J software by densitometry.

\section{Evaluation of hydrogen peroxide tolerance}

The stress oxydative caused by Hydrogen peroxide $\left(\mathrm{H}_{2} \mathrm{O}_{2}\right)$ was evaluated on the $29 \mathrm{~A}$. baumannii strains according to Heindorf et al, by disk diffusion [15]. Incremental concentrations of hydrogen peroxide used were: $1 \%, 5 \%, 10 \%$ and $20 \%$, and a disc with sterile milli-Q water to negative control. After $20 \mathrm{~h}$ at $37^{\circ} \mathrm{C}$, the inhibition halos formed around the paper discs were measured in millimeters $(\mathrm{mm})$. Three independent experiments were performed and the mean halos obtained (in $\mathrm{mm}$ ) were used for the statistic analysis.

\section{Evaluation of $A$. baumannii hemolytic activity}

The evaluation of hemolytic activity of the A baumannii studied strains was performed according to Tayabali et al [16]. In this test, six different kinds of blood were used: Sheep, horse and human. In the latter, four different blood types were tested $(O$, A, B, AB, all of them being $\mathrm{Rh}+$ ). Streptococcus pyogenes ATCC 19615 and Klebsiella pneumoniae ATCC 13882 strains were used as positive and negative controls respectively.

\section{Statistic analysis}

The Stata version 12.0 (STATA Corp. TX, USA) was used to perform the statistical analyses. Linear regression analysis was chosen to compare the variables.

Statistical analyses were performed using Software Prism5 (Grap Pad, USA), SPSS statistics software and Stata version 12.0 (STATA, USA). The tests used for the comparative were: Kolmogorov-Smirnov test, D'Agostino and Pearson and Shapiro-Wilk; for analysis of variance: ANOVA test followed by the Tukey test or Kruskal-Wallis test followed by Dunn. For all tests performed, a significant value of $p<0.05$ was considered.

\section{Results}

\section{Clinical and demographic profile of the study patients}

Overall, 29 MDR A. baumannii strains from 20 infected adult patients, $50 \%$ of them were female, and the mean age was 60.6 years ( \pm 17.6$)$. The mean hospital length of stay was 61.5 days $( \pm 41.4)$. All patients had at least one comorbidity, with heart failure (35\%) being the most prevalent (Table 2). 
Table 2: Frequency of comorbidities and patient intervention included in the study.

\begin{tabular}{|c|c|c|}
\hline Comorbidity $(n=20)$ & Frequency (n) & $\%$ \\
\hline Heart failure & 7 & $35 \%$ \\
\hline Immunosuppression & 6 & $30 \%$ \\
\hline Diabetes mellitus & 5 & $25 \%$ \\
\hline Chronic Renal Failure & 5 & $25 \%$ \\
\hline Hematologic neoplasia & 5 & $25 \%$ \\
\hline Cirrhosis & 2 & $10 \%$ \\
\hline Dialysis & 2 & $10 \%$ \\
\hline Chronic obstructive pulmonary disease & 1 & $5 \%$ \\
\hline Muscle- degenerative & 1 & $5 \%$ \\
\hline Solid organ neoplasm & 1 & $5 \%$ \\
\hline Pressure ulcer & 1 & $5 \%$ \\
\hline Bedridden & 1 & $5 \%$ \\
\hline Patient intervention & & $\%$ \\
\hline Admission in ICU & 16 & $80 \%$ \\
\hline Invasive devices & 19 & $95 \%$ \\
\hline Mechanical ventilation & 15 & $75 \%$ \\
\hline Tracheotomy & 7 & $35 \%$ \\
\hline Hemodialysis & 7 & $35 \%$ \\
\hline
\end{tabular}

Most included patients (95\%) received some invasive device during hospitalization and $75 \%$ of them underwent mechanical ventilation. All patients received one or more courses of antibiotic therapy during hospitalization, with a mean duration of 31.6 days ( \pm 25.0 ). Finally, five (20\%) out of the 20 patients died, three of them due septic shock.

\section{Detection of genes and association to the pathogenicity}

Figure 1 shows the frequency of the studied genes in $A$. baumannii strains. It is known that bap, as well as genes related to capsule and quorum sensing, were associated with biofilm formation. All strains had the bap and gaiU gene, wzc was present in $76 \%$ of them. In $72 \%$ of the strains both of the quorum sensing genes was observed. In a previous study, using the same strains, the quick biofilm production were evaluated in $4 \mathrm{~h} /$ at $37^{\circ} \mathrm{C}$, besides in $24 \mathrm{~h} / 25^{\circ} \mathrm{C}, 24 \mathrm{~h} / 37^{\circ} \mathrm{C}$ and $48 \mathrm{~h} / 25^{\circ} \mathrm{C}$ [13]. In this present study we also try to find an association between biofilm productions found before with the presence of the genes researched now. It was observed that all strains were able to form biofilm in at least some conditions, presenting better results at $48 \mathrm{~h} / 25^{\circ} \mathrm{C}$, in which $97 \%$ of the strains formed biofilm, and the non-formed strain contained neither wzc nor the quorum sensing genes. In this condition, among of the strongly adherent strains, $97 \%$ present at least one quorum sensing gene. At $37^{\circ} \mathrm{C}, 97 \%$ of the strains were able to form biofilm in only $4 \mathrm{~h}$ and, in this condition; all the four strongly adherent samples contained the wzc and quorum sensing genes. These results reveal the ability of this species to form biofilm and remain for long periods in the environment and, despite no tests related with expression genic had been done, all of them genes seems be importance in this process.
Some studies have shown that OMP33, as well as OMPA, are proteins that cause cytotoxicity in host cells, and since pneumonia associated with mechanical ventilation is the comorbidity caused by $A$. baumannii that affects the most of the patients, it is interesting to study the presence and the pathogenicity of these proteins in cells of the innate immune. This study also detected the presence of this genes and show that omp33 and ompA genes was present in $45 \%$ and $31 \%$ of the strains, respectively, that reveals their high prevalence in clinical strains.

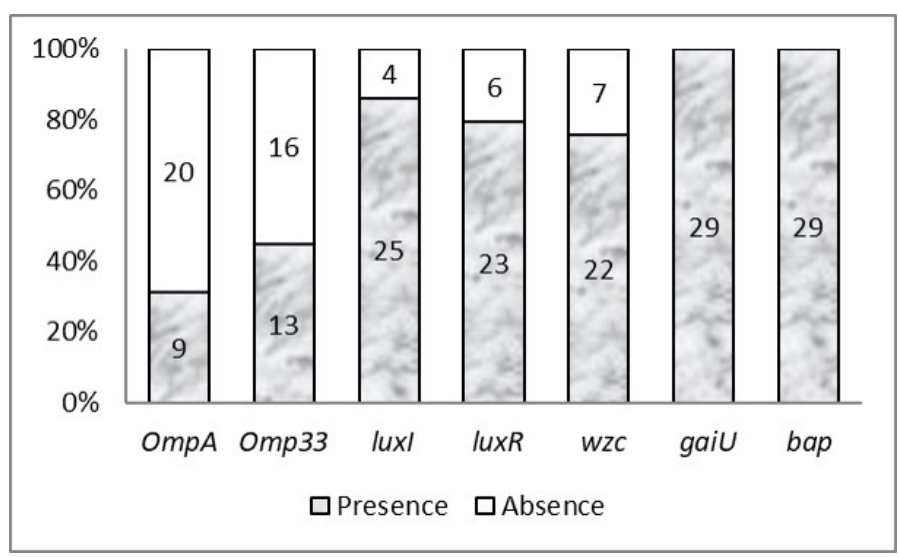

Figure 1: Frequency of genes related to pathogenicity of Acinetobacter baumannii strains $(n=29)$.

\section{Phenotypic detection of pathogenicity factors}

\section{Evaluation of $A$. baumannii tolerance to hydrogen} peroxide

Most of the tested strains (69\%) showed higher tolerance to $\mathrm{H}_{2} \mathrm{O}_{2}$ when compared to the reference strain. Further analysis presented significant difference in six strains (21\%), showing to be more susceptible to the $\mathrm{H}_{2} \mathrm{O}_{2}$ in comparison to the reference one (Figure 2). On the other hand, 14 (49\%) strains were more resistant to the $\mathrm{H}_{2} \mathrm{O}_{2}$, than the reference strain $(\mathrm{p}<0.05)$ (Figure 2). The overall results of this experiment strongly reveals the pathogenic potential of these strains, on this analysed parameter, since the oxidative stress response is critical to survive to this conditions that the bacterial pathogens may encounter due to the host immune response.

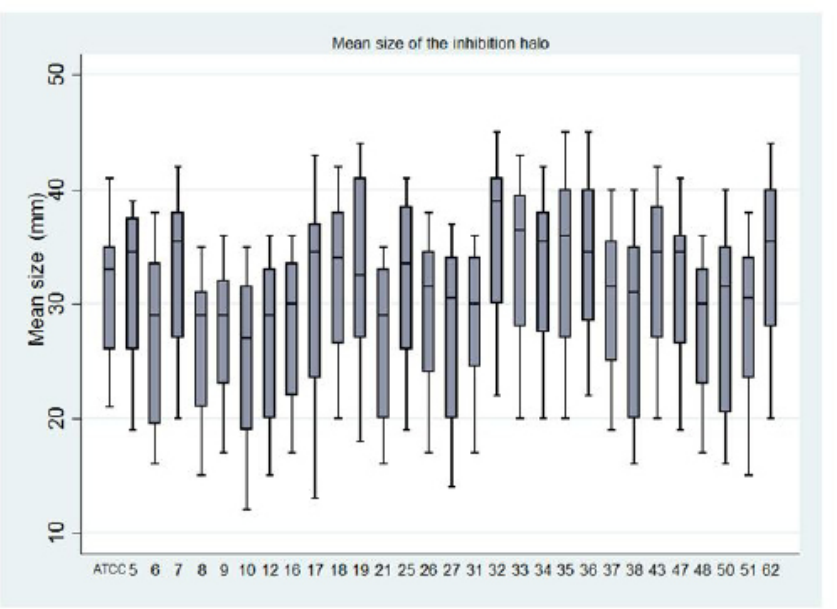

Figure 2: Mean size of the inhibition halos for the thirty Acinetobacter baumannii strains tested. 
24h infection- MOl:100

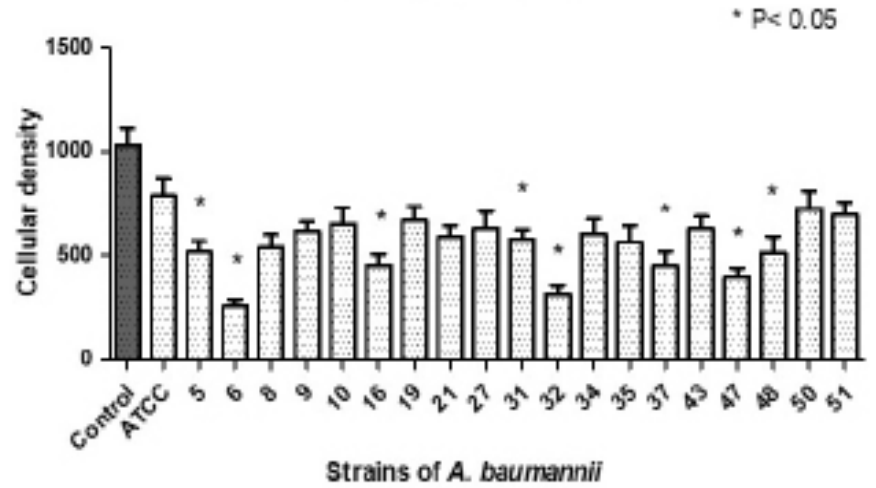

Footnote: MOI - Multiplicity of Infection.

Figure 3: Cellular density after infection of macrophages with A. baumannii strains, representing the samples in which a significant statistical difference $(p<0.05)$ was observed in relation to the control (without bacterial inoculum).

\section{Evaluation of hemolytic activity}

None of the strains of $A$. baumannii tested in the present study demonstrated hemolytic capacity to the erythrocytes of any of the blood types evaluated.

\section{Evaluation of cell death induced by $A$. baumannii strains}

Figure 3 describes the results of the macrophage culture in vitro assays. Different intensities of decrease in the cell density of macrophages were observed for all $A$. baumannii strains evaluated, including reference one, and this reduction compared to control (without bacterial inoculum) was statistically significant in $8(43 \%)$ clinical strains tested $(p<0.05)$.

\section{Discussion}

The knowledge of the mechanisms involved in the A. baumannii pathogenesis may be useful to better understand the interaction between this microorganism and the affected patients as well as potential target for therapy [2]. Rocha et al [17] evaluated the predictors of an unfavorable outcome in patients with A. baumannii infections at a university hospital in Brazil. The factors associated with mortality in patients with $A$. baumannii MDR, that was $39.7 \%$, were: age $>60$ years, presence of chronic diseases and use of invasive procedures. In our study, all patients presented one or more comorbitidy, and the majority underwent some invasive procedure, that was associated to mortality rate elevated (25\%).

The investigation of quorum sensing has allowed a better understanding of the host bacteria interaction [18]. The quorum sensing system effectors of Acinetobacter spp. are homologues of the LuxR (receptor) and LuxI (synthase) proteins. Previous studies have shown that surface motility mediated by this quorum sensing regulatory network plays a crucial role in the biofilm development of $A$. baumannii, by the production of N-(3- hydroxydodecanoyl)-L-HSL (3-hydroxy-C12-HSL) [20, 21]). Accordingly, the disruption of Luxl, which produces the A-HSL molecule results in a $30-40 \%$ reduction in the biofilm production comparing to that of the isogenic parental strain [31]. In our study, the quorum sensing genes was present in $72 \%$ of the strains, and $97 \%$ of the positive strains for both genes was strongly adherent at least one condition tested. At room temperature, $97 \%$ of the strains formed biofilm. Only one, that did not promote biofilm, also was negative to the quorum sensing genes. Our results reveals that these strains have high potential to form biofilm, especially in room temperature, and the regulation of biofilm formation may be linked to quorum sensing system.

Brossard et al [22] also demonstrated that the presence of biofilm-associated protein (Bap) is necessary for the formation of mature biofilm in medically relevant devices. In our study, we observed the presence of this gene in the all tested strains. Similar result was found in a study realized by Goh et al. (2013) in which 22 of the 24 strains of multi-resistant $A$. Baumannii to carbapenems carried this gene [23]. Together, this data's of the high prevalence show the important role that bap and quorum sensing genes plays in biofilm formation, although are needed further studies related to expression genic to clarify the process.

In relation to the polysaccharide capsule, mutants for the ptk (wzc) gene were completely cleared after 24 hours of infection in a model of soft tissue infection [24]. In the present study, $76 \%$ of the strains had the wzc gene and all strains had the gaiU gene. The latter is responsible for the synthesis of a UDP-glucose and is part of the central metabolism in E. coli [25]. Recently one study suggested that gaiU gene may be involved in more than one function on the cell [5]. Otherwise, genes such as wzc have been shown to be essential for the expression of the capsule on the cell surface in A. baumannii [24]. Although there are no studies relating these genes to the formation of biofilms, it is known that the presence of capsule is an essential factor in this process, so the high prevalence of biofilm-forming strains in this study may be due to the presence of these genes as well, in addiction to quorum sensing genes and bap, but further studies are needed to confirm this hypothesis.

Capsular polysaccharide could act as a barrier to penetration of the Reactive Oxygen Species (ROS) extracellular into the interior of the microorganism, lead to cell death [32]. In addition, previous studies have shown that mice deficient in ROS-producing enzymes are highly susceptible to $A$. baumannii infection [30]. Sun et al. (2016) have shown that differences in the production and expression of anti-ROS enzymes, such as the different types of catalases in Acinetobacter spp. resulted in different virulence phenotypes [10]. In a general context, in our study the tested $A$. baumanii strains presented differences in the sensitivity profile to hydrogen peroxide stress. Approximately half of the samples proved to be significantly more resistant to oxidative stress than the reference strain $(p<0.05)$, and interestingly they all presented the wzc and gaiU genes. These data strongly suggest that the presence of capsule could also be involved in this process, in addition to the formation of biofilm. However, further investigations are required to confirm this hypothesis.

In A. baumannii study has been reported that the presence of OmpA protein relates to induction of death in respiratory tract cells, besides antimicrobial resistance [26]. On the same way, Omp33 is a porine involved in resistance to carbapenems, induction of apoptosis and modulation of autophagy in host cells, besides biofilm formation [7, 27]. The study by Krzyminska et al. evidenced that $A$. baumannii induces apoptosis in epithelial cells [29]. In our study, $45 \%$ of the strains presented omp33, and $31 \%$ the ompA. Between the 19 clinical strains tested, eight led to a significant reduction in the macrophage count in vitro $(p<0.05)$, among them, $63 \%$ had both ompA and omp33 genes. Thus, these data suggest that these porins may indeed be involved in this process, but as there were different pathogenicity 
profiles, it also shows that may be assoaciated to a difference of expression of these porins [28], or even other factors inducing apoptosis not evaluated in our study.

Regarding to the hemolytic activity of $A$. baumannii, none of the strains evaluated induced hemolysis in the blood sample tested. Antunes et al [31] evaluated the hemolytic activity of A. baumannii strains. Sheep and horse blood agar were tested, and only in the latter all strains showed some type of hemolysis. In addition, it was noticed that the hemolytic activity was higher in liquid medium than in solid. This interesting result could explain why this species is still classified as non-hemolytic.

This study has some limitations. The small patient population and the retrospective nature of the study did not allow us to make a direct and significant association between the presence of the pathogenicity genes and the clinical outcome. Studies with a larger number of patients are required, as well as a more detailed follow-up of these.

\section{Conclusion}

In conclusion, all strains showed at least two of the seven genes associated with pathogenicity in this species. The high prevalence of biofilm-forming strains and the concomitant presence of bap, genes related to capsule and quorum sensing, suggests a strong correlation between these factors. The resistance to oxidative stress of the clinicals trains in relation to the reference one was also high $(p<0.05)$. None of the strains were able to hemolyze any of the blood types tested, but most of them induced macrophage death $(p<0.05)$ in vitro, and the death may have occurred due to the presence of ompA and omp33 genes. These interesting data suggested that virulent $A$. baumannii strains could trigger severe diseases. However, further studies on $A$. baumannii pathogenicity factors are need to find novel therapeutic agents or vaccines against this nosocomial pathogen.

\section{Acknowledgements}

To the following governmental agencies: Coordenação de Aperfeiçoamento de Pessoal de Nível Superior (CAPES), Conselho Nacional de Desenvolvimento Científico e Tecnológico $(\mathrm{CNPq})$, Fundação de Amparo à Pesquisa do Estado de Minas Gerais (FAPEMIG) and Pró-Reitoria de Pesquisa (PRPq) for the financial support.

Disclosure statement: The authors declare that there are no conflicts of interest.

\section{References}

1. Padovese $\mathrm{MC}$, Fortaleza $\mathrm{CMCB}$. Infecções relacionadas à assistência à saúde: Desafios para a saúde pública no Brasil. Rev Saúde Pública. 2014; 48: 995-1001.

2. Wong D, Nielsen TB, Bonomo RA, Pantapalangkoor P, Luna B. Clinical and pathophysiological overview of Acinetobacter infections: A Century of Challenges. Clin Microbiol Rev. 2017; 30: 409-447.

3. Longo F, Vuotto C, Donelli, G. Biofilm formation in Acinetobacter baumannii. New Microbiol. 2014; 37: 119-127.

4. Geinsinger E, Isberg RR. Antibiotic modulation of capsular exopoly saccharide and virulence in Acinetobacter baumannii. PLoS Pathog. 2015; 13: e1004691.

5. Kenyon JJ, Marzaioli AM, Hall RM, De Castro C. Structure of the K6 capsular polysaccharide from Acinetobacter baumannii iso- late RBH4. Carbo hydr Res. 2015; 29: 30-35.

6. Rumbo C, Tomás M, Fernández Moreira E, Soares NC, Carvajal $\mathrm{M}$, et al. The Acinetobacter baumannii Omp33-36 Porin Is a Virulence Factor That Induces Apoptosis and Modulates Autophagy in Human Cells. Infect Immun. 2014; 82: 4666-4680.

7. Moon DC, Choi CH, Lee JH, Choi CW, Kim HY, et al. Acinetobacter baumannii outer membrane protein A modulates the biogenesis of outer membrane vesicles. J Microbiol. 2012; 50: 155-160.

8. Jin JS, Kwon SO, Moon DC, Gurung M, Lee JH, et al. Acinetobacter baumannii secretes cytotoxic outer membrane protein $\mathrm{A}$ via outer membrane vesicles. PLoS One. 2011; 28: e17027.

9. Choi CH, Lee EY, Lee YC, Park TI, Kim HJ, et al. Outer membrane protein 38 of Acinetobacter baumannii localizes to the mitochondria and induces apoptosis of epithelial cells. Cell Microbiol. 2005; 7: 1127-1138.

10. Sun D, Crowell SA, Harding CM, De Silva PM, Harrison A, et al. KatG and KatE confer Acinetobacter resistance to hydrogen peroxide but sensitize bacteria to killing by phagocytic respiratory burst. Life Sci. 2016; 148:31-40.

11. Magiorakos AP, Srinivasan A, Carey RB, Carmeli Y, Falagas ME, et al. Multidrug-resistant, extensively drug-resistant and pandrugresistant bacteria: An international expert proposal for interim standard definitions for acquired resistance. Clin Microbiol Infect. 2012; 18: 268-281.

12. Smani Y, Domínguez-Herrera J, Pachón J. Rifampin protects human lung epithelial cells against cytotoxicity induced by clinical multi and pan drug-resistant Acinetobacter baumannii. J Infect Dis. 2011; 203: 1110-1119.

13. França RO, Costa PS, Milanez GL, Bomfim MR, Gonçalves R, et al. Molecular association of pathogenicity and resistance to multiple antimicrobials in Acinetobacter baumannii strains recovered from patients with diverse infectious diseases. J Bras Patol Med Lab. 2018; 54: 288-295.

14. Gonçalves R, Mosser D. The isolation and characterization of murine macrophages. Curr.Protoc. Immunol. 2015; Chapter 14: Unit 14

15. Magdalena H, Mahendar K, Christine H, Evelyn S, Gottfried W, et al. Impact of Acinetobacter baumannii Superoxide Dismutase on Motility, Virulence, Oxidative Stress Resistance and Susceptibility to Antibiotics. PLoS One. 2014.

16. Tayabali AF, Nguyen KC, Shwed PS, Crosthwait J, Coleman G, et al. Comparison of the Virulence Potential of Acinetobacter Strains from Clinical and Environmental Sources. PLoS One. 2012; 7.

17. Prata-Rocha ML, Gontijo-Filho PP, Melo GB. Factors influencing survival in patients with multidrug-resistant Acinetobacter baumannii infection. Braz J Infect Dis. 2012; 16: 237-241.

18. Papenfort, K, Bassler BL. Quorum sensing signal-response systems in Gram-negative bacteria. Nature Rev Microbiol. 2016; 14: $576-588$.

19. Niu C, Clemmer KM, Bonomo RA, Rather PN. Isolation and characterization of an autoinducer Synthase from Acinetobacter baumannii. J Bacteriol. 2008; 190: 3386-3392.

20. Bhargava N, Sharma P, Capalash N. Quorum sensing in Acinetobacter: An emerging pathogen. Critical Rev Microbiol. 2010; 36: 349-360.

21. Prashanth K, Vasanth T, Saranathan R, Abhijith R. Pagal M. Antibiotic resistance, biofilms and quorum sensing in Acinetobacter species, Antibiotic Resistant Bacteria -A Continuous Challenge in the New Millennium, 2012: 978-953. 
22. Brossard KA, Campagnari AA. The Acinetobacter baumannii biofilm-associated protein plays a role in adherence to human epithelial cells. Infect Immun. 2012; 80: 228-233.

23. Goh HM, Beatson SA, Totsika M, Moriel DG, et al. Molecular Analysis of the Acinetobacter baumannii Biofilm-Associated Protein. Appl Environ Microbiol. 2013; 79: 6535-6543.

24. Russo TA, Luke NR, Beanan JM, Olson R, Sauberan SL, et al. The K1 capsular polysaccharide of Acinetobacter baumannii strain 307-0294 is a major virulence factor. Infect Immun. 2010; 78: 3993-4000.

25. Hu D, Liu B, Dijkshoorn L, Wang L, Reeves PR. Diversity in the major polysaccharide antigen of Acinetobacter baumannii assessed by DNA sequencing, and development of a molecular serotyping scheme. PLoS One. 2013; 29: 8.

26. Cerqueira GM, Peleg AY. Insights into Acinetobacter baumannii Pathogenicity. IUBMB Life. 2011; 63: 1055-1060.

27. Smani Y, Fàbrega A, Roca I, Sánchez-Encinales V. Role of OmpA in the Multidrug Resistance Phenotype of Acinetobacter baumannii. Antimicrobial Agents Chemother. 2014; 58: 1806-1808.

28. Sato Y, Unno Y, Kawakami S, Ubagai T, Ono Y. Virulence characteristics of Acinetobacter baumannii clinical isolates vary with the expression levels of omps. J Med Microbiol. 2017; 66: 203212.
29. Krzyminska S, Frackowiak H, Kaznowski A. Acinetobacter calcoaceticus-baumannii complex strains induce caspase-dependent and caspase-independent death of human epithelial cells. Curr Microbiol. 2012; 65: 319-329.

30. Qiu H, Kuolee R, Harris G, Chen W. Role of NADPH phagocyte oxidase in host defense against acute respiratory Acinetobacter baumannii infection in mice. Infect Immun. 2009; 77: 10151021.

31. Antunes L, Carattoli A, Visca P. Deciphering the Multifactorial Nature of Acinetobacter baumannii. Pathogenicity. PloSOne. 2011.

32. Kashef N, Hamblin MR. Can microbial cells develop resistance to oxidative stress in antimicrobial photodynamic inactivation? Drug Resist Updat. 2017; 31: 31-42. 